\title{
Urbanization and Solid Waste Management Challenges, in Addis Ababa City, Ethiopia
}

\author{
Yitbarek Andualem Mekonnen Prof.Dr.Huseyin Gokcekus \\ Faculty of Civil and Environmental Engineering \\ Departments of civil engineering, Near East University, Mersin 10 Turkey
}

\begin{abstract}
Urbanization is refers to the population shift from rural to urban area and gradual increase in the proportion of people living in urban areas. It is growing issue, in Addis Ababa city the numbers of population is rapidly increasing time to time every year, this has many challenge on community of different infrastructures like solid waste management properly in city. This study review the major influences of urbanization on solid waste management and consequent of solid waste production and their management problems in Addis Ababa city starting from 2013-2017. There are many challenges of solid waste management in Addis Ababa city through the year, these are urban management problem, Physical constraints, budgeting and low community participation in city is majors. Inadequate management of municipal solid waste has many impacts on community every year. These impacts are socio- economical impact and environmental impact.
\end{abstract}

Keywords: sources, generation, collection, transport, disposal, waste management, challenges, Addis Ababa city DOI: $10.7176 / C E R / 11-5-02$

Publication date:June $30^{\text {th }} 2019$

\section{INTRODUCTION}

What is urbanization? Urbanization is general increments of population and the numbers of industrial resolution. It is a growing issue in one city or country (Shushu Li 1 and Yong Ma 2, 2014). This indicates the numbers of people expand from per-urban to urban and rural to urban area by different means. Due these reason then numbers of population increasing time to time in city in short periods, especially capital city of many countries from both developing and developed countries, this condition is the same from Addis Ababa (AA) city, Ethiopia. According to CSA the numbers of AA city starting from 2012 up to now, the numbers of population in 2012 is 3.6 million, 2013 is 3.71 million, 2014 is 3.95 million, 2015 is 4.28 million, 2016 is 4.6 million and 2017 is 6.6 million this indicate the growth rate of the city population is very fast through every year. Therefore, the urbanization from Addis Ababa city is uncontrolled time to time through the year; this causes many problems on community of the city every time, like municipal solid waste management's.

Municipal Solid Waste (SW) is collected of various wastes generated by households, commercial and industrial organization, institutions such as schools, hospitals, care homes and prisons, and from public spaces such as streets, markets, slaughter houses, public toilets, bus stops, parks, and garden (Biruk Abate Fenta, 2017) and also during the processing and disposal of solid waste in one city properly without influencing community's health of city and environments around city and re-use and recycling. Solid waste management is contain all governmental, economical, lawful, planning, development and solved all waste problems by engineering principle. The solution of solid waste may be very difficult interdisciplinary fields such as political discipline, and regional arrangement, topography, financial, public health, communications of people, demography, conservation, demography, sociology, as fine engineering and materials science(Ali Mohammed $1 *$ and Eyasu Elias2, 2017).

The present solid waste management system of AA city is mostly relies on the municipality to address it and there are few private participants working on a very small scale compared to the quantity of work required in the sector. The technique used by the municipality is basic open dumping or disposal after collection from different institutional and households place called Repi about $15 \mathrm{~km}$ from the city centre (Meaza Cheru, 2016). The disposal has been running for the last 66 years without appropriate management of solid waste. But now a day there is a few approaches to answer the issues and no important effects have happened, because the town is expanded every time to time out of the government's services capability. At Addis Ababa city appropriate requirement of Municipal solid waste management performs is still unsatisfactory and imperfect (Ali Mohammed1* and Eyasu Elias2, 2017). In study area is illegal removal of waste on open areas, street, ditches and river area is considered as routine task of inhabitants. The efforts made by the municipality to change the condition in the town are also inadequate as it compared to the extent of the challenges, so, in order to decrease this condition and accomplish proficient solid waste management system of the city. Municipal solid waste management challenges are getting difficult as a result of urbanization in Addis Ababa. Population growth, extension of informal resolution and business, absence of appropriate regulatory mechanisms, poor awareness of the population on municipal authority coupled with poor governance are exacerbating the Municipal Solid Waste Management (MSWM) issues. 
The technique of MSWM of Addis Ababa city at present handled is indefensible, shapeless, unproductive, uncoordinated and unrepresentative (Hayal D, Hailu W, Aramde F, 2014). The solid waste production is growing, as the tendency promises still dynamically fueled by populace boom and commerce development in quantity, kind and stage of danger. The consideration of the population and how they relate themselves to the SWM challenges is significant. There are clear issues in gathering, transportation and final disposal. The scattered solid wastes are creating environmental air pollution posing health risks for human being, domestic and wild animals. The poorly managed open dumping site, which is currently causing air, land and water pollution. The site is posing practical health risks especially to the inhabitants surrounding it.

\section{Challenges of urbanization in AA city}

Urbanization in Addis Ababa has many challenges on different infrastructure of city, like municipal solid waste management, water supply, sewer system, air pollution, bad city planning, traffic and congestion, housing, food security, affect environments and economy of the city direct or indirect especially low levels of income communities.

Housing is the numbers of residential area in city. The housing in Addis Ababa city is rapidly increasing time to time because most people enter into AA city from different country direction inside and outside from country by various purposes. Because Addis Ababa city is capital city of Ethiopia and the biggest one city from African countries and also large city in the world by numbers of population, according SCA estimation the numbers of population at current time is around 6.6 million. Therefore, the numbers of population required the houses and produce more municipal solid waste day to day and natural ecosystem in the process of to construct different urbanization activities very day. But not all population gate their housing area from city because the population uncontrolled time to time in city.

Traffic and congestion: the traffic in AA is very high due to various visitors coming from different places of the town region and outside country and also most African governments coming most of time because the Africa union office is found in AA city through the year. This condition causes many problems on city populations such as noise, congestion and confusion of traffic make it seem suicidal to business enterprise onto the street.

Traffic in AA city influencing the working time because most of time the traffic roads closed at morning time in all direction through a week, this affect their productivities, especially during Africa union meeting.

Shortages of water supply: adequate and safe water is important for all population. But in Addis Ababa city there is not adequate and safe water supply because the numbers of population is increasing rapidly out of forecasting of water supply system. Due to this reason shortage of water is occurred through the year in city. Therefore urbanization is one major factor for water scarcity in AA city, this affects most low level economy community of population to buy water by high prices every day from shops especially drinking.

Lack of Sewer system: sewer system is one of infrastructure in any city, but in AA city is install some parts of city. This is every time affected by huge amounts of population because numbers of population increase and also amount of sewage is increasing time to time with their proportion of city population. Rapidly increasing city population influencing the design periods of sewer system because the system cannot transmits high amounts of it size, this cause breakdowns of sewerage pipeline time to time and required huge amounts of money for operation and maintenance purposes.

Food security: increase the numbers of population in city required more amounts of food and also reduces the lands of agriculture time to time and also the cost of food is increasing rapidly. Most of population in AA city is employers of governments, NGO, private institution, merchants and some people are daily labors, then all people in AA city buy food every time, this affects the cost of food from market and different restaurants and hotel every time and influencing low level salary people in city.

Air pollution: the huge amounts of traffic, smoky form different factories and use of coal or wood fires for cooking and heating and carbon dioxide released from huge population often create abroad dark covering of air pollution in city. Air pollution is depends on the city activities and numbers of industrial area in city. Air pollution is affects highly the city population and as whole country and also other countries by different means. In AA city more carbon dioxide is released from more factories and traffic roads every time this affects most people and environments and also vegetables around city.

Economical impact: economies of low income communities are affected indirect by urbanization because the housing cost is very high for different job and every things are high prices day to day in AA city, it is difficult situation for these populations survival in city, the most low economy levels people move other city without their interest.

Environmental impact: as whole the urbanization in AA city is affect the environmental quality by different way. These above factors are happened already the environment is affected indirect by population of city.

\section{Solid waste management (SWM) in Addis Ababa city}

Municipal solid waste management in AA city start from generation area up to disposal areas, then municipal 
solid waste management is managements of waste generation, waste separation and handling, collection, storage and processing, transport and final disposal at disposal area but it is not appropriate ways of collection and transport in AA city.

\subsection{Main sources of $\mathbf{S W}$ in Addis Ababa city}

Solid waste contains many types of solid waste which, generator from different sources with different quantity in city. The main source of municipal solid waste in AA city is domestic waste, commercial waste, institutional waste, industrial waste, construction waste, street sweeping etc.

Domestic municipal solid waste: is the solid waste produced from residential area by different human activities, like food cooking, cleaning different thing, by old cloths, fuel burning, obsolete utensils, furniture activities and equipments. Mostly this waste is affect the city because the sources is depends on numbers of population in city especially food waste.

Commercial waste: the solid waste is generated from restaurants, hotels, shops and etc; each commercial area contains packaging materials, office supplies and food waste. In Addis Ababa city there are more numbers of commercial area and they generates more amounts of solid waste per day through a year, especially food waste and plastic waste.

Institutional waste: this waste is produce from public schools, public clinics and hospital, governmental offices, NGO and private offices and different institutional offices in city of AA. Some institution produces hard waste on communities of city, like clinical and hospital offices which is hazardous and infectious materials.

Industrial waste: this waste is generated from different industrial area in city. These wastes are various types depends on types of industry and it products, such as food waste, packaging materials, plastics, paper, different chemicals and different types of papers. But industrial waste is difficult to water bodies during disposal time, it affect highly because it contains huge amounts of chemical before and after process of fabrication production.

Construction waste: these waste produced from construction areas, this waste is highly produced in AA city time to time because AA city rapidly increasing by different infrastructure construction every year. The construction waste are soil, stone, brick, concrete, ceramics, packaging and wood materials during and after construction produced. This waste affects the city quality and environments by different means in city every year. Street sweepings: These wastes is produced from street sweeping area, which produce soil, dust, paper and also contains household waste dumped along roads, vegetable and fruit, animal manure, drain cleanings and plant remains.

Characteristics of these waste is vary from one sources to other sources and its impact is also vary depends on types of generations. Therefore, the professional and effectual management of solid waste produced in city, sufficient understanding and information regarding the characteristics of solid waste is important. Because easily control and treat and also reduce the impact on city population and environments.

\subsection{SW generation in Addis Ababa city}

All populations are generates solid or liquid waste every day in city. But waste generation rate is varying from one person to other persons and one kebele to other kebeles. These various are in amounts, rate, composition and degrees of hazard and also management activities. In AA city huge amounts of municipal solid wastes are produced day to day corresponding to numbers of population in city. In AA city the average generation of solid waste is $0.45 \mathrm{~kg}$ per person per day (Ali Mohammed1* and Eyasu Elias2, 2017). The quantities of solid waste are directly proportion with the numbers of population of city. That mean the numbers of population is increase and also the production of solid waste is increase. To compare the numbers of population and quantities of solid waste starting from 2013-2017 of the city as follows below table 1.

Table.1The numbers of population and quantities of SW in AA city 2013-2017

\begin{tabular}{|c|c|c|}
\hline Year & Population & Solid Waste (kg/c/day) \\
\hline 2013 & 3710000 & 1669500 \\
\hline 2014 & 3950000 & 1777500 \\
\hline 2015 & 4280000 & 1926000 \\
\hline 2016 & 4600000 & 2070000 \\
\hline 2017 & 6600000 & 2970000 \\
\hline
\end{tabular}

Sources, CSA and different published papers 


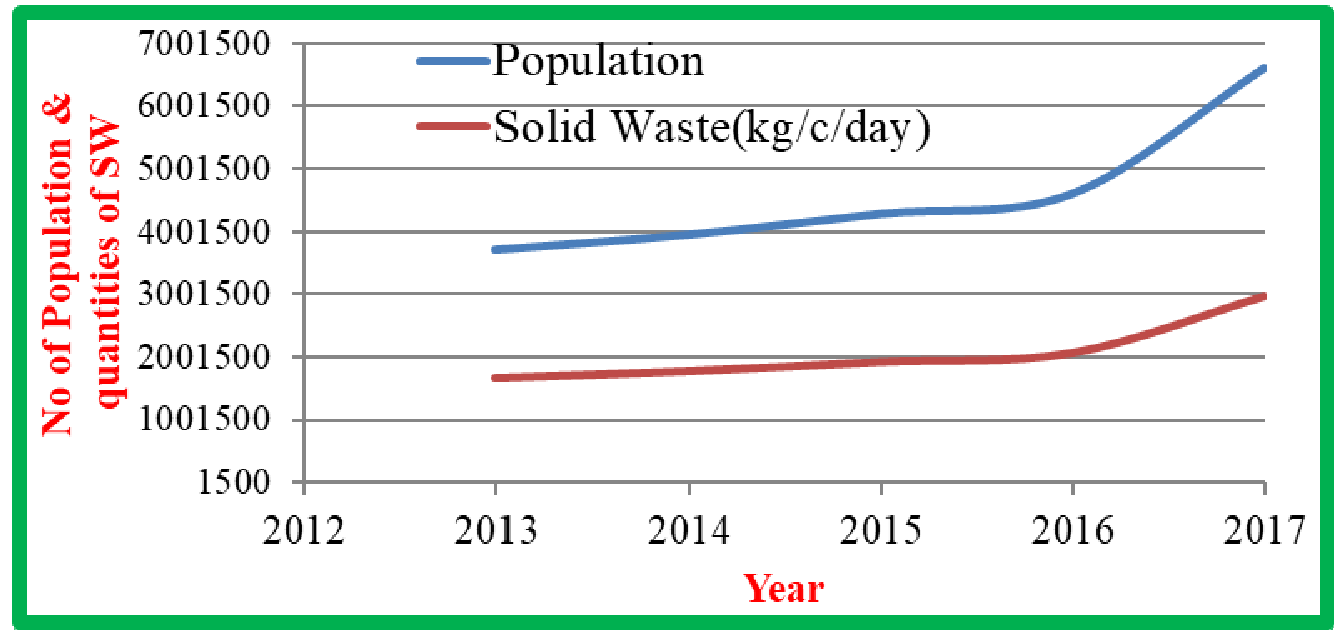

Figure.1: show the proportion of population and solid waste in AA city

This graph shows that the solid waste production is directly proportional to the numbers of population in city every year. That means the numbers of population increase also the production of solid waste is increase by quantity.

\subsection{Composition of SW in Addis Ababa city}

The composition of the MSW of Addis Ababa is presented is very low. The type of source (household, commercial, etc), revenue level, season and some actions will have pressure on the composition of SW. The present composition can have diverse image than depicted below in the table 2. Particularly the plastic bags waste stream is rising radically in the last few years. The SWM status report (Meaza Cheru, 2016), shows that $60 \%$ the total wastes are organic, $15 \%$ comprises of recyclables materials and others are about $25 \%$.

Table.2: The composition various types of solid waste in AA city

\begin{tabular}{|c|c|c|}
\hline No & Major constituents & percentage \\
\hline 1 & Ash, dust, fines & $65 \%$ \\
\hline 2 & Combustible leaves and grasses & $15 \%$ \\
\hline 3 & Vegetables and fruits & $4.20 \%$ \\
\hline 4 & Rubber and plastics & $2.90 \%$ \\
\hline 5 & Non-combustibles & $2.50 \%$ \\
\hline 6 & Papers & $2.50 \%$ \\
\hline 7 & Textiles & $2.40 \%$ \\
\hline 8 & Wood & $2.30 \%$ \\
\hline 9 & Bones & $1.10 \%$ \\
\hline 10 & Metals & $0.90 \%$ \\
\hline 11 & Glasses and ceramics & $0.50 \%$ \\
\hline
\end{tabular}

Sources, Meaza Cheru, 2016

This indicate not composition of all solid waste in the city every day and through the year, this causes various factors on city community by different ways.

\subsection{Collection of SW in Addis Ababa city}

Collection of solid waste is the process of picking up of waste from sources by collection materials. Municipal solid waste collection is one of the principal mechanisms of waste management's in city.

Commonly, there are three essential types of solid waste collection apparatus: these are human powered, animal powered, and engine powered. In the Addis Ababa condition, both motorized and human collection apparatus are being used. Considering to the human aspect, transportation of municipal solid wastes to the containers is possible using hands and hand pushed carts. In each Kebele, planned locations are assigned where collectors make standing by for the motorized collection. The majority of the areas in the city are unapproachable for motorized collection; so, the human powered collection system is mostly used. The current trend of storage bins used in the city of Addis Ababa is not standardized bins, and dust bins are located only on main roads with the assumption that those roads are the popular ones. For temporary storage, households arrange various types of receptacles such as baskets, card boxes, and bamboo made containers, cans, plastic bags, barrels, etc. Only $65 \%$ of the MSW is collected and disposed off by the municipal in the land fill, only $5 \%$ is recycled, $5 \%$ composted and the $25 \%$ is dumped in unrestrained surrounding like in or on empty spaces, streets and river banks in Addis Ababa city (Ali Mohammed1* and Eyasu Elias2, 2017). 
There are four types of municipal waste collection methods in Addis Ababa city, such as community bin, curbside collection, block collection and door to door collection.

Community bin collection: Community bins are located in suitable place where community members carry waste and throw it in. This technique is moderately cheaper than other technique, and the majority broadly adopted technique in western countries. For this technique to be adopted it is significant that bins are covered, aesthetic, attended regularly, kept clean, easy to handle, and separate bins are provided

Block collection: collection vehicles arrive at a particular place or a set day and time to collect waste from households. Households bring their waste containers and empty directly into the vehicle. This method requires a higher home owner cooperation and scheduled service for homeowner collaboration.

Curbside collection: house owner is accountable for placing containers to be emptied at the curb on collection day and for returning empty containers to their storage location until the next collection dates.

Door to door collection: waste is located at door step at a set time when waste collector arrives. In this technique, collector of waste has the accountability to collect waste individually. This technique is very suitable for households, however requires home owner teamwork. Majority of households are using door to door service (84\%) (Ali Mohammed1* and Eyasu Elias2, 2017) in Addis Ababa which can indicate the community's adaptation to better service. High income households use door to-door collection system than in middle and low income households. In Addis Ababa, there are various factors who are directly concerned in a broad range of solid waste management activity including Non-Governmental Organizations(NGOs), private institution, persons or young children from poor households are the pioneers in providing door to-door solid waste pre-collection service in the city. The households using door-to-door collection service were asked if they had seen any development after using the service. All of the households who were using the service responded that they had seen development in the area of solid waste condition in their environment (Biruk Abate Fenta, 2017). Therefore, the pre-collection of AA city as follow,

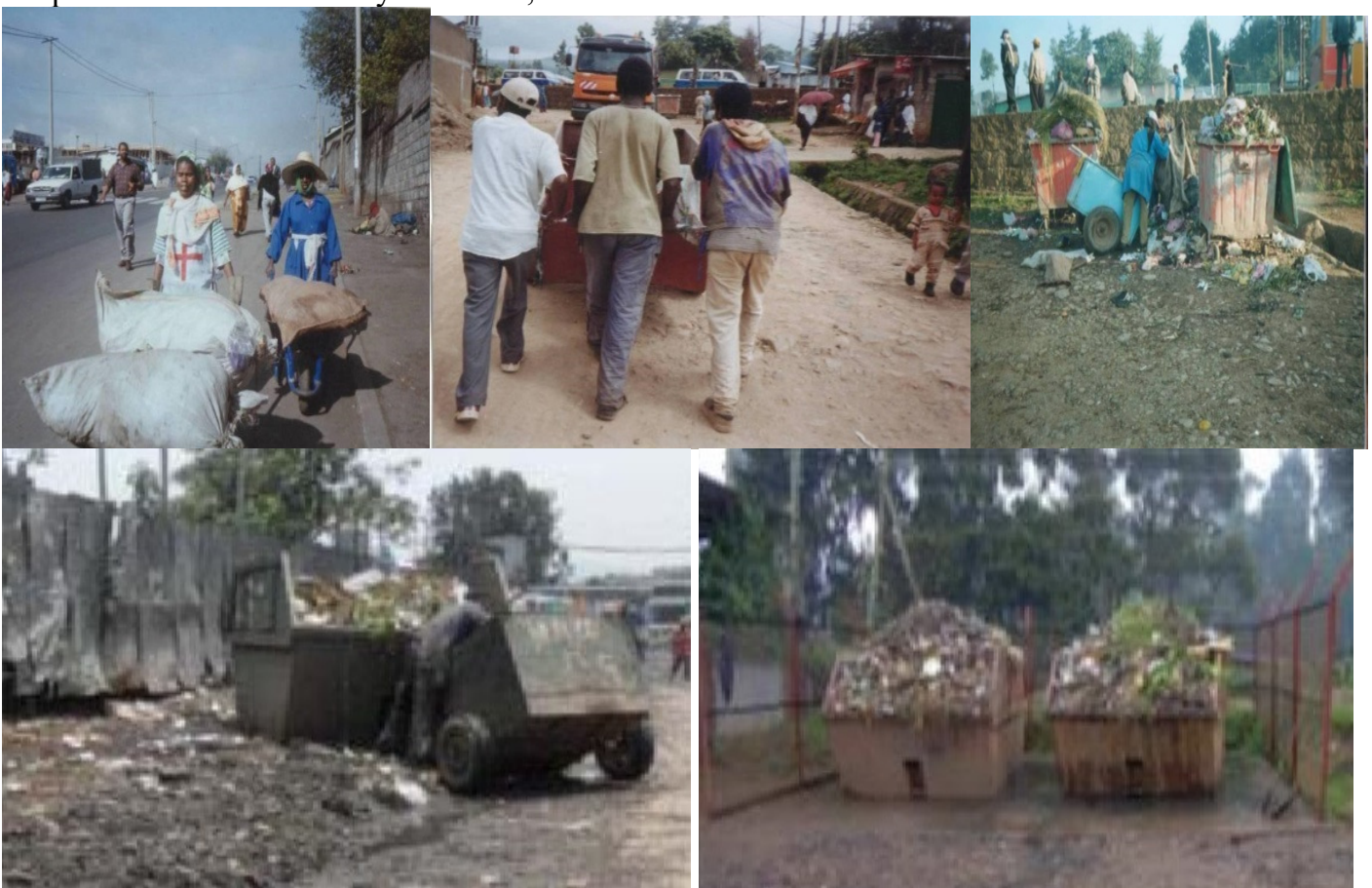

Sources, Ali Mohammed1* and Eyasu Elias2 (2017)

Figure.2: collection systems of solid waste in AA city

Therefore, these types of solid waste collection is hard to city community because cause various types of factor on their health and economy especially poor economy population in city.

\subsection{Transfer and Transportation of solid waste in AA city}

These activities are associated with transfer of wastes from public storage facilities to collection Vehicle and the subsequent transport of wastes to disposal site in AA city. Transfer refers to movement of waste or materials from primary collection vehicle to a secondary, larger and more proficient transport vehicle, when location of final disposal site is $15 \mathrm{~km}$ from the center of the city. The transfer and transportation of solid waste in AA city is two operation systems which are direct discharge and storage discharge operation system. This operation system is used to collect SW from different place, when the direct discharge is each refuse truck empties directly in to larger transport vehicles but storage discharge refuse is first emptied from collection trucks in to a storage pit location (Ali Mohammed1* and Eyasu Elias2, 2017). 
The draft report (2017) of Clean and Green Addis Ababa Society shows that out of 72 trucks, on average only 36 trucks work daily because of the old age of trucks, lack of proper and timely maintenance, lack of proper care for the trucks by the drivers during working time and managerial problems. This show there is not the proper transports of solid waste in city because half of the estimated trucks are not functioned at this time but the numbers of population and amounts of solid waste is increase rapidly time to time parallel without any types of gap.

\subsection{Disposal of solid waste in Addis Ababa city}

Disposal is the final functional element in solid waste management system. Disposal activities are associated with final dump of solid wastes directly to a landfill site. Today disposal of wastes by land filling or land spreading is the ultimate fate of all solid wastes whether they are residential wastes, or residual materials from materials recovery facilities.

Waste disposal is one of the most significant management activities which need to be carefully planned. With regard to waste disposal at transfer station, the study identified that almost all solid waste generated in households is disposed together. I.e. there is no sorting habit of organic waste at the household level.

Until the start of 2017, Addis Ababa city was using the area of 'Reppi or Koshe' (Koshasha) (Meaza Cheru, 2016) which is open dumping site for all types solid wastes in city generated every time, which has been in operation since 1950s receiving over750 tons of waste per day and also 273750 tons for one year but the total years of this disposal area is 1950-2016 is 66 years, then the total storages of solid waste averagely $66 * 273750$ is 18067500 tons, without any types of treatment and reuse or recycling. It is located $15 \mathrm{~km}$ south West of the city covering about 25 hectare (Meaza Cheru, 2016). It is bounded by ring road and residential areas straight without any protection for man and animals. It is managed by Addis Ababa City Sanitation, Beautification and Park Development Agency (AACSBPDA). The method of disposal was crude open dumping; the waste is placed on flat land: hauling by truck, spreading and leveling by bulldozer and compacting. Since the start of 2016 , 'Reppi or Koshe' has been closed because it is full and affects the human beings and animals but there is not any types of mechanism to reduce the factors and reuses of this disposal SW by different purposes in city and around the city region. After 2016 the disposal place is shifted to another new disposal site constructed around Kotebe area, north of the city, although it did not last long. These cover 765 tons of solid wastes are being produced daily and for one year 279225 tons but it is expected to increase significantly in the future because the numbers of population is rapidly increasing time to time in study area. In AA city the SW is not use any types of treatment and reuses for other purposes to reduce the load on the disposal area and to increase the periods of disposal areas. This show after some time all parts or sides of city is constructed by dispose of the solid waste, this causes different types of disease on community of the city, affects the water bodies which are surface or ground water, animals and all living things around it and also reduce the quality of the city compare to other city. Way of disposals of SW in AA city starting from 1950-2016 is as follow:
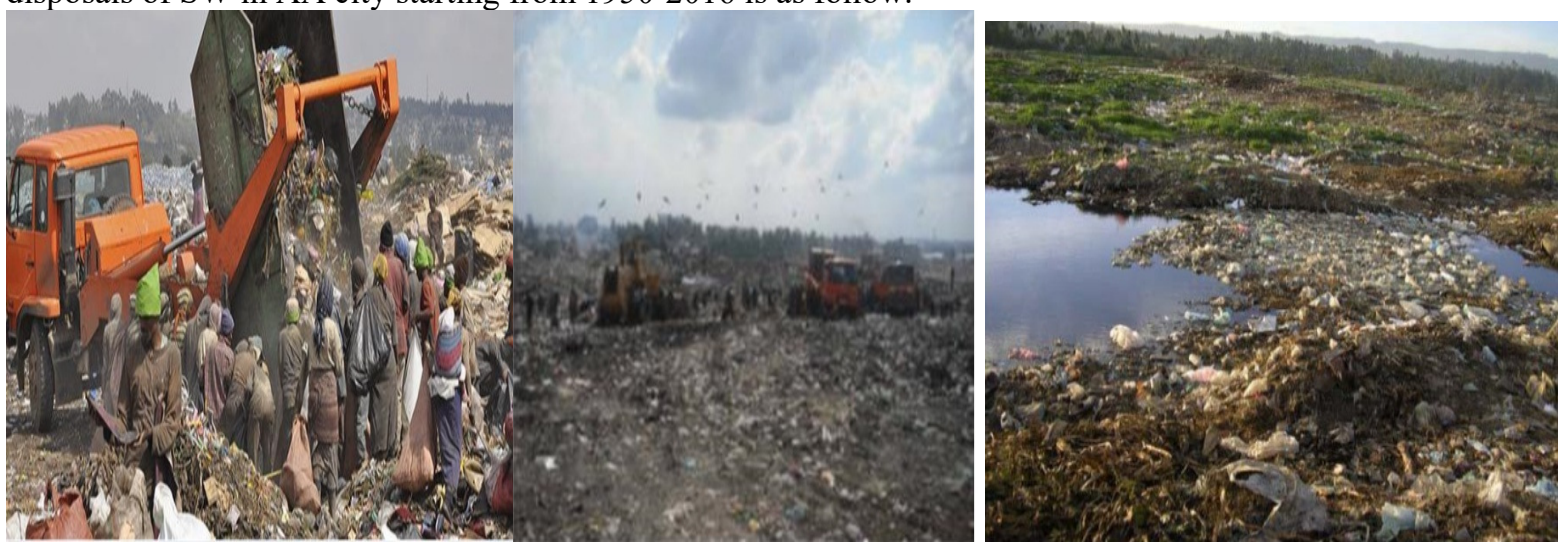

Sources: Meaza Cheru, 2016

Figure.3: Reppi or koshasha SW disposal area (1950-2016) and campaction AA city.

According to above figure, the disposal SW is hard during and after disposal on human being animals and environments by direct or indirect by different means.

\section{Challenges of SWM in Addis Ababa city}

There are many challenges of municipal solid waste management in Addis Ababa city through the year, these are urban management problem, Physical limitation, budgeting and low community participation in city is majors.

Urban management problem: urbanization is good for city by different means like developments of different infrastructure in city and creates different job for community of low level income but it have many challenges to mange populations of city because people is growth rapidly time to time and also produce huge amounts of SW 
every day through the year. In AA city the urban management problem is very huge by different means that means the numbers of urbanization is fatly increased every year, this is difficult to manage the different types of solid and liquid waste in city because every time in AA city produce huge amounts of solid waste depends on the numbers on population existing in city. Due to this reason the city administration cannot easily control and manage the solid waste in city every day produced. These required more numbers of skilled full manpower to manage trucks to transport, huge area to disposal and more daily labor to collect the waste from different places of waste production of city. This cause the numbers of challenges on community of the city every time, like water related diseases on population health, their economy, reduce quantity and quality of both surfaces water and groundwater around the town especially near disposal area and also reduce the quality of the city. Therefore, the government must be control and properly manage the urbanization and SW which generated from different places of city every day string from sources up to disposal area. And also check every time the amounts of waste produced from city especially from the residential area because $80 \%$ of solid waste is municipal waste in AA city through the year.

Physical limitation: The main limitation to waste management includes physical and economic challenges in AA city every year. Physical limitation to waste management include absents of proper planning, insufficient infrastructure and expansion rapidly the numbers of population without any gap. Totally physical planning of the city causes different factors in terms properly to manage of solid waste produced from city population daily from different station of waste management areas, such as waste generation, collection, transport and disposal. This has main challenges on economy of the city community and reduction of their development and also city.

Budgeting: budget of the city one of the major challenges proper managements of municipal solid waste in Addis Ababa city time to time past and current time, due to this reason there is not solid waste treatment and reuse in AA city it is only disposal without treat and also there is not recycle for other purpose, because there is not adequate budget for this activities.

Low community participation: in AA city the community participation is very low to manage properly the solid waste which produced from different areas of the city with various quantity and quality. Because without community participation any types of development and managements system is impossible in city, the different communities have various energy, knowledge, economy and time to work to manage properly the solid waste in city. then the city administration should be create awareness on community the aims of solid waste manage from sources up to disposal area every day, the effects of solid waste on their health care, the responsibility of every person to manage at sources of their home or working place every day because the waste is produced by human activities every time and also reuses or recycling these solid and liquid waste for other useful purpose at sources and after disposal area by separating used waste and unused waste. Therefore, community participation is better for adequate managements of municipal solid waste in city because without community management system is not good for only the governmental organization, community must be share idea and different opinion how to manage, how to reuse or recycle the solid waste.

\section{Impacts of inadequate managements of SW in AA city}

Inadequate management of municipal solid waste has many impacts on community of AA city every year. These impacts are socio- economical impact, environmental impact and etc.

Socio-economic impacts: most of solid waste in AA city is collected and disposal from open area but it have many challenges on socio-economies of the city population every year during collection, transport and disposal and also after disposal because there is not treatment after disposal of SW in AA city. Some solid waste solid waste causes the reduction of community productivity and their economy development; these wastes are metals and discarded foods. Inadequate collection, transport or improper disposal of household waste can have adverse health impacts on community direct or indirectly every time. These wastes are affects the groundwater and surfaces water, then people of city is used this water by different domestic purposes especially low income levels of community in city; this cause's different water related diseases. Particularly on children and women of the population because they are fetch water for their domestic activities every day city, that means from the whole parts of Ethiopia country looking and fetching of water is only children and women and also collect and disposal of the house solid waste. Therefore, inadequate managements of solid waste are have many impacts on socioeconomies of the AA city population by different means, especially on poor or low economy levels of community.

Environmental impact: inadequate managements of municipal solid waste have many effects on environment or surrounding. Due to inadequate municipal solid waste collection and disposal considerable amounts of waste ends up in open dumps or drainage system and on landfill, this affects water bodies which are both surface water and groundwater by their quantity and quality and also causes air pollution at disposal areas and near areas, among the causes of air pollution and unpleasant odour, especially the area where lack of garbage collection containers. It also leads to loss of productive land due to the presence of non-biodegradable materials which are disposal without selecting and contamination of soil, ground and surface waters. Addition to this some hazardous 
domestic wastes can filter down through the soil and contaminate groundwater and reduce its quantity and quality especially around disposal areas. This affects human being, plants, soil, plants and water quality and quantity. Therefore, this affects the drinking water quality and quantity of the city, because AA city currently uses both sources of water which are groundwater and surfaces water supply such as Aba-Samuel Dam, one of the main sources of water supply to the city and there are many surfaces and groundwater in city but their quality is very low because there is not liquid and solid waste treatments. Addition to the environmental challenges in AA city is lack of sewerage system.

\section{CONCLUSION}

Urbanization is one of the current issue in Addis Ababa city due to rapid increasing of numbers of population time to time without any gap, this have a great challenges on different infrastructures of city, like domestic water supply, municipal solid and liquid waste management, housing place and on other infrastructures. Then the city government must be manage the rapid growth rate of urbanization in city and fulfill various infrastructures, especially suitable municipal solid waste management proportional to urbanization numbers of populations in city.

Municipal solid waste is a waste which generated from different urban areas with various quantity and quality. Municipal solid waste management is managements of solid waste properly starting from sources up to disposal area without affecting the city community's economy, social life, quality of city and environments and also reuses or recycles these wastes for other purpose before and after treatments. But in Addis Ababa city, there are not proper managements of municipal solid waste staring from sources up to disposal area because the management is simply disposed without any types of treatment before or after disposal and they cannot reuse by different purpose these waste, this affects the city community by direct or indirect ways every year, such as their economy and socio life and influence the environments especially surface water and groundwater in both their quantity and quality.

Inadequate managements of municipal solid waste in city cause many challenges on city and population, such as reduce the quality of city and plans of city landscape structures and causes different water borne or water related diseases on city community and also reduce the life of people and their productivities. This is not only city population it affects as whole country region environments around it by direct or indirect means, it cause air pollution in city and other regions because high amounts of carbon dioxide is released from it at sources, collection area and disposal area every time.

Therefore, the governments should be manage the municipal solid waste staring from sources up to disposal areas properly and must be treat these waste and reuse for other different purposes to reduce the loads on disposal areas and create the job and economy for the city community to work and reuse these waste by different function through their life. The city administration must be every year or time to check the effects of the municipal solid waste at sources, collection areas and disposal area and identify the impact of it on community of city and other country sides and also solve these impacts in short time. Unless the impacts of municipal solid waste is hard on communities of city and also other country sides region population after some years, especially reduction of potable domestic water supply, because water is important for all population that means water is life, but without safe and clean water the human cannot be survive on the land, these situation is very hard for low level economy population in city and totally affects the quality of city and human life.

Generally, the city administration must be properly manage the municipal solid and liquid waste from every populated areas, treat and reuses for different purposes, this is create the working job for unemployment peoples and reduce the numbers of unemployed peoples in the city and country and to increase the economies of the peoples and also country.

To create the awareness from total community of city about causes and impacts solid waste on their health, economy, domestic water supply and totally on environments without properly manage from starting sources up to disposal area, then every community could be take the responsibility to protect and manage waste their own waste generation area after their working every day, this reduce the load on treatment plane and disposal area and reduces smells and odour from city and peek the qualities of the city and also reduces the water related diseases and increasing both surfaces and groundwater quantity and quality.

\section{Reference}

Ali Mohammed1* and Eyasu Elias2 (2017), Domestic solid waste management and its environmental impacts in Addis Ababa city

Amimul Ahsan, Moetaz Elsergany, Muhammed Alamgir and Shahriar Shams (2014), Assessment of Municipal Solid Waste Management System in a Developing Country

Bjerkli Camilla Louise, (2014), urban services and governance: The case of solid waste management in Addis Ababa, Ethiopia, Trondheim, Norway: Norwegian University of Science and technology department of geography. Available at:https://brage.bibsys.no/xmlui/handle/11250/265502 
Biruk Abate Fenta (2017), Waste management in the case of Bahir Dar City near Lake Tana shore in Northwestern Ethiopia: A review, Received 7 April, 2017; Accepted 26 May, 2017

Central Statistical Authority, "Household consumption and expenditure survey 2010/11", Statistical Bulletin (No. 563). Addis Ababa, Ethiopia. 2012.

Chekole, Z. F. (2006), Controlling the Informal Sector: Solid Waste Collection and the Addis Ababa City Administration 2003-2005. Master Thesis, NTNU, Trondheim Norway.

Edwards S (ed.) (2010). Ethiopian Environment Review No. 1. Forum for Environment, Addis Ababa

Federal Democratic Republic of Ethiopia (FDRE), "Solid Waste Management Proclamation", Federal Negarit Gazeta of the FDRE, Proclamation No. 513/2015, Addis Ababa, Ethiopia

Forum for Environment, FFE (2010), Assessment of the Solid Waste Management System of Bahir Dar Town and the Gaps Identified for the development of an ISWM Plan". In Ethiopian Environment Review, Addis Ababa

Hayal D, Hailu W, Aramde F. (2014) Assessment of the contemporary Municipal Solid Waste Management in Urban Environment: The case of Addis Ababa Ethiopia. Journal of Environmental Science and technology 7(2): 107-122.

Hardeep Rai Sharma (2016), Municipal Solid Waste Management in Debre Berhan City of Ethiopia

Jejaw Legesse 2008. Review on Municipal Solid Waste Stream Classification and Management Practices in Addis Ababa City. M.Sc. Thesis Presented to the School of Graduate Studies of Addis Ababa University.

Koyachew EK (2016). The problem of solid waste management and people awareness on appropriate solid waste disposal in Bahir Dar City: Amhara region, Ethiopia. 3(1):1-8

Mahmood Zohoori(2017), Municipal Solid Waste Management Challenges and Problems for Cities in LowIncome and Developing Countries, Volume 6 Issue 02, 2017, ISSN-2319-7560

Mazhindu E, Trynos Gumbo T, Tendayi Gondo T. (2012). Waste Management Threats to Human Health and Urban Aquatic Habitats: A Case Study of Addis Ababa, Ethiopia (http://creativecommons.org/licenses/by/

Meaza Cheru(2016), Solid Waste Management in Addis Ababa

Mengist Hailemariam, Assegid Ajeme (2014), Solid Waste Management in Adama, Ethiopia: Aspects and Challenges World Academy of Science, Engineering and Technology International Journal of Environmental and Ecological Engineering Vol: 8, No:9, 2014

MelakuTayye, 2008, Household Solid Waste Generation Rate and Physical Composition Analysis, In Jimma Town Ethiopia, A Masteres Thesis presented to the school of graduate studies of Addis Ababa University. Addis Ababa, Ethiopia.

M. Coffey, A. Coad, "Collection of Municipal Solid Waste in Developing Countries", United Nations Human Settlements Programme (UN-HABITAT). Nairobi, Kenya. 2010.

Municipal of Addis Ababa/MAA 2002, Project Proposal for Addis Ababa, Municipal Proposal for Addis Ababa Municipal Solid Waste Management Program. Unpublished Paper

Nigatu Regassa 1, Rajan D.Sundaraa ${ }^{2}$ and Bizunesh Bogale Seboka ${ }^{2},(2011)$.Challenges and Opportunities in Municipal Solid Waste Management: The Case of Addis Ababa City, Central Ethiopia

Reports (2015), Overview of addis ababa city solid waste management system

Romanus Ugwuanyi and Theresa Chima Isife (2017), Urbanization and solid waste management challenges in Nigeria, International Journal of Science and Engineering Applications Volume 6 Issue 02, 2017, ISSN2319-7560 (Online)

Regulatory and Institutional Reform in the Municipal Solid Waste Management Sector, Ethiopia, Strategy for the development of a framework for PSP in SWM in Ethiopia, Vol. 1, Strategy, World Bank (WB) (2012). What a Waste: A Global Review of Solid Waste Management, Urban Development Series Knowledge Papers.

Sharma, H.R., Abebe, T., Admassu, M., Teshaye, T., Aseffa, T., \& Emana, M. (2011), "Municipal Solid Waste Management and Community Awareness and Involvement in Management and Practice: an overview and a case study from Gondar town of Ethiopia”, Int. J, Environment and Waste Management, 7(3/4), 294304

Smith. 2010. What is Solid Waste Management? Retrieved from (http://www.wise greek.com/ what-is-solidwaste-managment.htm) web page accessed, august15)

Tadesse Kuma 2004. Dry Waste Management in Addis Ababa City. A paper presented on teaching workshop from January5/16th in Addis Ababa.

Tamiru, A. (2014). "The impact of uncontrolled waste disposal on surface water quality in Addis Ababa", SINET: Ethiopian Journal of Science Vol. 24, No.01, pp. 93-104.

Tessema.F. (2010), Overview of Addis Ababa City Solid Waste Management, Presentation at Workshop on Solid Waste Management in Addis Ababa, Ethiopia

Leulsegged Kasa, Dawit Alemu, Gete Zeleke and Fisum Gebre Hagos(2011), Impact of urbanization of addis abeba city on peri-urban environment and livelihoods

UN-HABITAT (2009), Solid Waste Management in the World's Cities: Pre-Publication Series, UN-HABITAT, 
Nairobi. World Bank (WB) (2004).

United Nations Population Fund (UNFPA) (2008). Federal Democratic Republic of Ethiopa Population Census Commission .Summary and statistical Report of the 2007 Population and Housing Census, Population Size by Age and Sex. December 2008, Addis Ababa

Vikrant Tyagi1*, Solomon Fantaw1, H. R. Sharma2(2016), Municipal Solid Waste Management in Debre Berhan City of Ethiopia ISSN 2224-3216 (Paper) ISSN 2225-0948 (Online) Vol. 4, No.5, 2016

YEBALEWORK BIBISSO DODA (2014), assessment of municipal solid waste management case of hawassa town, southern nation, nationalities and people's regional state, M.A thesis, Haramaya University

Zebenay Kassa, (2010), the Challenges of Solid Waste Management in Urban Areas, the Case of Debremarkos Town, Addis Ababa University, Ethiopia. 